\title{
OCTAVIO PAZ: POESÍA E HISTORIA
}

Hace poco el Presidente Luis Alberto Lacalle de Uruguay observó que ha habido una desvalorización general de las ideologías en la vida política. Según él, el pragmatismo y el ejercicio de "una buena gestión" han reducido la importancia de todos los programas ideológicos desde el socialismo revolucionario hasta la reacción organizada de derechas ${ }^{1}$. Encuentro, y no sé si exagero, un paralelo de ese pragmatismo en la crítica y teoría literaria de nuestros días. La compleja y muchas veces confusa herencia del estructuralismo exige una lectura técnicamente pragmática, que se basa siempre en el cómo del texto, y a expensas del qué. El mismo Octavio Paz parece haber sido influido por esa tendencia, y en muchos poemas desde Blanco hasta Árbol adentro nos está diciendo cómo los escribe mientras los escribe.

Por otra parte Paz conserva, en discreta medida, su inmunidad. Su obra poética es una zona libre en que la imagen imprevista y la sorpresa siguen siendo inviolables. En efecto la poesía - la poesía en general- es esa zona, situada precariamente entre la realidad cotidiana y la conciencia histórica individual; y tal vez los poetas son menos prisioneros, menos víctimas intertextuales - por decirlo así- de las obras literarias precedentes que los novelistas de las suyas. Así, los poemas resultan ser espacios deslindados que se hallan en una relación cada vez más ambigua con la realidad y la historia. Por eso los poetas son los más libres y al mismo tiempo los más incómodos de los escritores.

Un buen libro siempre es algo más, o algo diferente, de lo que parece ser. Me refiero a la paradoja fundamental de todas las obras que se suelen calificar de importantes, o grandes: la paradoja de ser algo y de no ser ese algo al mismo tiempo. Don

1 Garfias 1991. 
Quijote es y no es un libro de caballerías; Cien años de soledad es ur relato cuyas realidades e imaginaciones se contradicen y simultá neamente se complementan; en Cantos de vida y esperanza las exu berancias que el poeta celebra se transfiguran en las angustia que padece.

Piénsese también en $E l$ arco y la lira de Octavio Paz: ensay sobre la poesía que no se limita a ser un ensayo sobre poesía. $F$ último de sus subtítulos nos pone en estado de alerta: "Poesía historia”. ¿De qué se trata? ¿De una dicotomía, o de una com plementariedad?

El lector de El arco y la lira está en el mismo dilema que el au tor: es decir, la poesía - o el arte aparentemente puro de la con posición rítmica mediante palabras- es una operación que no : puede realizar ni analizar sin tomar en cuenta muchas cosas qi no son poéticas; entre ellas, la que más nos importa por ahor: la historia. Pienso que lo esencial de la historia - tanto desde punto de vista del escritor como del lector- es la conciencia c una progresiva complicación. En un lúcido ensayo sobre el fus cionamiento de la información en el mundo contemporáneo, Je emy Campbell afirma lo siguiente: "Así como pasa por siglos milenios, la historia es una crónica de novedades - nuevas estruct ras, nuevos organismos, nuevas civilizaciones, nuevas ideas. I información, un modo de medir la novedad, no disminuye sir que aumenta a través de los años"?2.

En lo que sigue se verá cómo Octavio Paz lucha mediante 1 palabras, sea en verso o en prosa, por descifrar ese monstruo $\mathrm{cr}$ ciente - la información- "signos en rotación", nuevos desc brimientos que apuntan nuevos misterios. Así, la informaci acumulativa es la materia proteica de nuestra época.

\section{Aproximación a la modernidad}

El arco y la lira, el mejor libro de Paz en prosa, es una teoría la poesía en el contexto de la modernidad. Pero es, además, u experiencia de la poesía en ese mismo contexto. Como todos poetas en varia proporción, el autor de $E l$ arco revela en su ol una complementariedad de experiencia y teoría. En el siglo la Modernidad es el campo de batalla en que esa relación se a ma. Por lo mismo, modernidad es un término sospechoso, ig

\footnotetext{
${ }^{2}$ Campbell 1982, p. 84.
} 
que muchos otros que acaban en ismo o dad o empiezan con post o inter o auto. Los académicos salpicamos con esos prefijos y sufijos nuestros cuadernos y páginas y pizarras: modernidad, posmodernismo, intertextualidad, postestructuralismo, autorreflexividad. No se vive ya en el tiempo de las definiciones -entre otras razones por el fenómeno expansivo de la Información ya aludido- sino en el tiempo de los interrogantes.

Modernidad es, como dice Paz en su reciente discurso de Estocolmo, "una palabra en busca de su significado"3. El mayor significado de la modernidad que él nos ofrece en El arco y la lira, Corriente alterna y Los hijos del limo es el de una síntesis - mejor dicho, una relación interdependiente - de creación y crítica que se manifiesta en cada obra. El moderno se esfuerza por funcionar simultáneamente en calidad de escritor y lector activo; es decir, crítico. Es una conciencia que va descubriendo figuraciones de su subconciencia y que, al hacerlo, se vuelve cada vez más irónica. No nos equivoquemos. En sus constantes referencias al proceso de crear poemas, Paz habla de una idealidad que se persigue, no de una realidad que se alcanza. Él mismo se coloca entre los dos extremos que nos indica en el capítulo final de Los hijos del limo; entre "el sí pasional y el no reflexivo"; entre el "lenguaje-lava" de Pablo Neruda en Canto General y la "dura transparencia" de Muerte sin fin de José Gorostiza: dos monumentos: uno a "la locuacidad", el otro a "la reticencia",

\section{DOS SENSIBILIDADES FRENTE A LA HISTORIA}

Piénsese ahora en el Tiempo, fenómeno que no existe en sí, pero que continua y persistentemente vamos materializando en una forma u otra. El tiempo me interesa porque es el puente abstracto que vincula dos trayectorias orgánicas: la colectiva de la historia y la personal de la poesía.

Dos citas de personajes muy diferentes, pero de la misma nacionalidad y época nos podrían servir para aclarar este pensamiento sobre la paradoja del tiempo, verdadero vínculo y medida de la historia y de la poesía. Tanto la primera -en verso librecomo la segunda - breve aforismo- intentan reducir la historia a las dimensiones y al ritmo de la experiencia personal.

\footnotetext{
${ }^{3}$ PAZ 1991, p. 12.

${ }^{4}$ PAZ 1974, p. 191.
} 
1) es la resurrección de las presencias,

La poesía no es la verdad: transfigurada en la verdad del tiempo no fechado.

la historia

2) Hay grandes momentos histórieos que son verdaderamente momentáneos.

La primera es de Octavio Paz, y se encuentra en su poema "Nocturno de San Ildefonso"5. La segunda es de un pensador más conocido que Paz — no por lo que ha escrito sino más bien por lo que en muchas y muy variadas circunstancias ha dichoMario Moreno (alias “Cantinflas"'). Los versos citados son una resurrección transfiguradora, el medio poético de recobrar y al mismo tiempo rehacer el pasado. El aforismo, perla representativa del ideario de su autor/actor, es la forma del cómico de desentenderse de las grandes —o, pará su autor- inútiles cuestiones: en su propio lenguaie, no tanto contra los intelectuales como con. tra todo lo indirecto: "Ni me lo platiques".

\section{LOS DESCUBRIMIENTOS}

Pensemos ahora en un gran momento histórico que, no obstant la acelerada sabiduría de Cantinflas, resultó ser más que momen táneo. Cerca del principio de su novela Daimón, el argentino Abe Posse declara que "el 12 de octubre de 1492 fue descubierta Eu ropa y los europeos por los animales y hombres de los reinos se. váticos"6. A continuación Posse escribe que la mayoría de lc extranjeros que invadieron los territorios americanos eran unc mezquinos oportunistas que "organizaban sus delirantes visic nes del tiempo bajo el nombre Historia (una especie de metafís ca pista de carreras)" 7 , cuyo símbolo más sagrado (la Cruz) eı también un instrumento de tortura.

Por negativo que parezca, aquel punto de vista no provier de la Leyenda Negra. Recordemos que la Leyenda Negra fi una revisión no hispánica de los hechos para una crítica del de potismo español y los rigores de la Inquisición. La alusión c Posse nos interesa más bien porque refleja la conciencia colectrir

\footnotetext{
${ }^{5}$ PAZ 1976, p. 79.

${ }^{6}$ Posse 1989, p. 26.

${ }^{7}$ Ibid., p. 27.
} 
de una prolongada desventaja histórica. Desde el Descubrimiento Recíproco de 1492 los hispanoamericanos se han acostumbrado a ver a los no-invitados colonos que siguieron las huellas de Colón como los primeros Otros en intervenir en el destino de su continente. (Otro, no se olvide, es la four-letter-word fundamental en la lírica y el pensamiento de Octavio Paz.) La historia latinoamericana, a su vez, se puede explicar en términos de una genealogía no sólo dispersa sino siempre diferente y como desvinculada de las demás historias.

Gabriel García Márquez destaca esa genealogía en forma concreta en Cien años de soledad, como lo hace Carlos Fuentes en forma abstracta en su ensayo "El tiempo de Octavio Paz" al identificar a éste como "hijo de México, hermano de América Latina, hijastro de España, hijo adoptivo de Francia, Inglaterra e Italia, huésped familiar y afectivo de Japón y la India, bastardo (como hoy lo somos todos) de los Estados Unidos" 8 . Hijastro de España - se podría añadir- de un modo comparable al del protagonista de Cervantes, formalmente reconocido por éste como hijastro suyo. Don Quijote en su época, como el poeta mexicano en la suya, atraviesa el páramo social con una creciente sensibilidad por su alienación. Pero en su juventud los poetas suelen transformar su enajenamiento en una búsqueda de solidaridad. Esto, combinado con la circunstancia histórica y el entusiasmo político, estimuló a Paz a salir por primera vez de su país, hacia España. "En 1937 abandoné, al mismo tiempo, la casa familiar, los estudios universitarios y la ciudad de México. Fue mi primera salida"'.

Los tres poetas hispanoamericanos más importantes del siglo xx coincidieron en España en el momento crítico de la modernidad de aquel país: la Guerra Civil. La presencia de César Vallejo, Pablo Neruda y Octavio Paz allí y entonces fue simbólica además de física. Para Vallejo España en estado de guerra fratricida sería la confirmación última de su sentimiento trágico de la vida; para Neruda, un cambio de perspectiva humana que lo llevaría del expresionismo esotérico de sus Residencias hacia el compromiso político y social; para $\mathrm{Paz}$ a la edad de 23 años fue el verdadero comienzo de su odisea literaria. Con todos sus horrores la contienda española fue también una guerra para poetas: la vida cotidiana convertida en drama, ecos de un llamado a la solidaridad,

\footnotetext{
${ }^{8}$ Fuentes 1970 , p. 156.

${ }^{9}$ PAZ 1988, p. 26.
} 
la realidad distorsionada por Picasso e independientemente $\mathrm{d} \epsilon$ Picasso -y, desde un principio, el presentimiento trágico.

La guerra civil en España fue, en efecto, el rito de iniciaciór de Octavio Paz, la experiencia compartida que habría de ilumi nar en su imaginación el turbulento matrimonio de la poesía cor la historia. La idea de que la historia y la poesía son temporal : estructuralmente circulares se expresa en muchas partes de si obra, sobre todo en Piedra de sol (1957), que empieza y termin con los mismos cinco versos y medio:
un sauce de cristal, un chopo de agua, un alto surtidor que el viento arquea, un árbol bien plantado mas danzante, un caminar de río que se curva, avanza, retrocede, da un rodeo y llega siempre:

Es de notar que la primera estrofa y la última palabra d poema terminan con dos puntos, signo de lo inacabable.

\section{4. "Somos un extremo de Occidente",}

Como pensador y como poeta Paz se expresa a menudo en dic tomías. La unicidad de su visión se complementa con la "ot] dad' de sus pensamientos; el poeta escribe y lee simultáneame te sus textos; el presente es "perpetuo"; las "conjuncione orientales y las "disyunciones" occidentales se yuxtaponen; pr sía de comunión conduce a poesía de soledad; y finalmente, lectura a Freud con lo que parece ser la ayuda de Norman Brown en Life Against Death ${ }^{10}$ lo lleva a recordar que la dualic del sol y del excremento tiene su gracioso paralelo en esa o dualidad del rostro y de otra parte del cuerpo por la cual $\mathrm{Pa}$ Francisco de Quevedo sienten gran curiosidad. En su prólog la Nueva picardía mexicana de A. Jiménez cita al respecto unas fónicas metáforas de Quevedo: "La voz del ojo, que llamar pedo, / ruiseñor de los putos..."11

El anhelo que Paz expresa en El arco y la lira por una "en nación" de la poesía es el equivalente modernista (modernist,

10 BROWN 1959.

11 PAZ 1979b, p. 264. 
mo se entiende en los países de habla inglesa) del anhelo romántico de Unamuno por la inmortalidad en Del sentimiento trágico de la vida. Nos dice en "Los signos en rotación" que aunque la sociedad nunca es poética "una sociedad sin poesía carecería de lenguaje: todos dirían la misma cosa o ninguno hablaría"'12. Aunque una encarnación de la poesía en la forma de una realidad social es tan imposible como una encarnación unamuniana en la inmortalidad, la sociedad la necesita y de alguna manera la utiliza.

Con todo, a pesar de todo, el mundo se impone. El darse cuenta de aquella intrusión es un elemento vital de lo que Paz, Harold Rosenberg y otros han llamado la tradición moderna o tradición de lo nuevo (otra vez, la dicotomía), porque la intrusión histórica presagia disrupción.

Como teórico de la modernidad Paz parece atribuir a la palabra dos significados principales: dicotomía y dispersión.

1) Por dicotomía entiendo las rupturas existenciales y las contradicciones ya mencionadas, en el sentido de que el proceso creador y la conciencia crítica son recíprocos, y que la palabra tradición en la era moderna se define sólo a la luz de las escisiones y cambios que la afectan y transfiguran.

2) Con dispersión me refiero a la fragmentación inevitable del mundo que conforme a la mayoría de las religiones y mitos fue en un pasado remoto un mundo unido y solidario. Parte de esa concepción unitaria es la idea e imagen de España en función de Madre Patria de Hispanoamérica. Cualquier historiador de literatura hispanoamericana se da cuenta de la sobrevivencia y persistencia de esa madre; por otra parte la hija - mejor dicho las hijas - son quienes son: crecen, caminan, se desvían, se orientan, se transforman; adquieren la doble conciencia de su pasado perdido y de su presente disperso.

A la luz de los dos conceptos (dicotomía, dispersión) se entiende con mayor claridad las circunstancias y modos en que los hispanoamericanos - a partir del individualismo y espíritu independiente de Sor Juana Inés de la Cruz- empiezan a "sentirse distintos"'13 de los españoles. En "Alrededores de la literatura hispanoamericana' y en otros ensayos Paz repite el concepto periférico de la cultura que Ortega y Gasset había aplicado antes a España. En 1937 Ortega le escribió desde París a E. R. Curtius

12 PAZ 1967, pp. 253-254.

${ }^{13}$ Paz 1979a, p. 28. 
que la mayoría de los europeos pensaban que España era un país muy raro y solían soslayar las cosas españolas así como las personas se alejan al encontrarse ante el espectáculo de unos "cadáveres insepultos". Sin embargo, agregó Ortega, los españoles son "total y puramente europeos, precisamente son la variedad más extrema de lo europeo, muy próxima a lo "completamente otro"'14. Años después Paz, a su vez, parece haber extendido lí imagen extremista de Ortega a los hispanoamericanos, incluso á sí mismo, al observar que éstos no eran más que "un extrem de Occidente - un extremo excéntrico, pobre y disonante"'. A reconocer la presencia de "algunos críticos literarios excelentes' lamenta que "en Hispanoamérica no ha habido ni hay un movi miento original y propio"'15.

En verdad faltaba un movimiento intelectual en el sentido eu ropeo tradicional, pero en la segunda etapa de su carrera literari (a partir de su vuelta a México desde España en 1938) Paz recc noció y celebró una nueva forma de unidad hispánica estimulad en gran parte por la emigración de artistas, escritores y pensadc res españoles a Hispanoamérica y, sobre todo, a México. Má que nada, conforme a su parecer de entonces, la poesía era cc munión; las nociones de una utopía anti-totalitaria parecían vt rosímiles; y el mundo hispánico parecía experimentar un nuev renacimiento: "lo hispánico es algo mucho más rico que la liter: tura local española", escribió en $1941^{16}$.

Esa segunda etapa de su obra poética (a grandes rasgos década de los cuarenta y la primera mitad de los cincuenta) fi también el semillero de su pensamiento crítico. En la primes edición de El laberinto de la soledad (1950) define la circunstanc mexicana como la búsqueda de identidad histórica mediante ur lucha inacabable entre el amor de la forma y el amor de la espo: taneidad. En ese Laberinto de 1950, que empezó a escribir vari años antes, Paz expresa ya su intuición de "lo otro", refiriénd se a los mexicanos como huérfanos históricos y espirituales. Pe al mismo tiempo afirma que la literatura mexicana es un eleme to nuevo y vigoroso de la cultura universal y, además, parte $c$ amplio enriquecimiento hispanoamericano de la cultura españo]

En sentido positivo está diciendo que la cultura hispánica puede definir en términos de una continua expansión intelectui

14 Ortega y Gasset 1963, p. 341.

${ }^{15}$ PAZ 1979a, pp. 43 y. 45.

${ }^{16}$ PAZ 1988, p. 259. 
En sentido negativo, desde la primera edición de El arco y la lira (1956), elabora una cancelación sistemática del porvenir; o, en la perspectiva más poética de "Los signos en rotación" (1965), "Nuestro tiempo es el fin de la historia como futuro imaginable o previsible" 17 , porque el tiempo, en el desierto abstracto de la tecnología, es "discontinuo" y se nos pierde.

La otredad se vuelve exterioridad. La tecnología borra los conceptos antiguos del espacio y del tiempo. El centro no está por ninguna parte. Un mundo precario absorbe al paisaje, así como Paz lo visualiza en uno de sus mejores poemas:

en los tallos de hierro

Un día

estallarán las lámparas

Un día

el mugido de los motores

ha de apagarse

estas casas serán colinas

Un día

otra vez

el viento entre las piedras

hablará a solas

Oblicua

entre las sombras

insombra

ha de caer

casi azul

sobre la tierra

La misma de ahora

la nieve de hace un millón de años ${ }^{18}$

Éstas son las impresiones que el poeta viene desarrollando desde la segunda edición de El arco y la lira (1967), ya en su madurez escéptica, que lo lleva a practicar una poesía y una poética cada vez menos históricas y más fantasmagóricas. Cada vez más el mundo es algo por descifrar como de paso, mientras que él realiza su odisea lingüística. Gada vez más el mundo es una abstracción:

${ }^{17} \mathrm{P}_{\text {AZ }}$ 1967, p. 265.

18 PAZ 1976, P. 19 
Ver el mundo es deletrearlo.

Espejo de palabras: ¿dónde estuve?

Mis palabras me miran desde el charco de mi memoria ${ }^{19}$.

Entre las fantasmagorías del presente y los fantasmas de la niñez y juventud que desfilan por Pasado en claro se sitúa el sujeto lírico. Posiblemente la residencia prolongada de Paz en el extranjero en calidad de diplomático, su inmersión por los años sesenta en culturas asiáticas, su alienación de la política de izquierda en los últimos veinte años, y una creciente fascinación por el lenguaje autónomo y espectral a partir de Blanco - es decir, cierta tendencia de creer y luego, sobre todo entre universitarios, de teorizar que el lenguaje debe desplazar a la realidad más que absorberla - lo han alejado del corazón histórico de gran parte de lo que escribió entre la primera edición de El laberinto de la sole. dad y Posdata. En mi país Dana Gioia, un poeta que es tambiér un hombre de negocios, atribuye la disminuida influencia cultu. ral de la poesía en los Estados Unidos al creciente aislamiento d los poetas en cerradas comunidades académicas ${ }^{20}$. Esta tenden cia me parece menos amenazante en México y el resto del mund hispánico que en Norteamérica, aunque la inclinación esotéric: de Paz es más notable en Árbol adentro (1987) que en Libertad baj palabra (1949) o en La estación violenta (1957).

Con todo, no hay por qué suponer que lo escrito por Paz es una etapa anterior haya sido anulado por lo que escribió des pués. Esto es porque hasta los poetas más abstraccionistas n pierden del todo su conciencia histórica, y porque quiéralo o nc todo poeta y artista retiene algo de su experiencia del mund real. Nadie mejor que el mismo Paz podría haber resumido ‘ curso de la reciprocidad histórica intermitente entre Hispanoz mérica y España. Él se ha referido a las tres etapas de ese proct so: 1) el reconocimiento mutuo desde la Conquista hasta 1: guerras de Independencia, 2) un período de relativo distanci: miento desde los años veinte del siglo xIx hasta 1936, y 3) el r comienzo de afinidades culturales desde los primeros días de Guerra Civil española.

El mundo hispánico que no se limita ni a España ni a Hisp noamérica sigue reclamando su atención. Hoy ese mundo pare

${ }^{19}$ PAZ 1978, p. 15.

${ }^{20}$ Giola 1991, p. 94. 
carecer de centro, pero la interrelación de obras y lecturas, el retorno intermitente de fantasmas desde el tiempo caótico del Descubrimiento Recíproco ya mencionado de 1492 y -más que nada- el enigma compartido de un futuro indescifrable les han aportado a las comunidades hispanas de toda la tierra un nuevo estímulo para la solidaridad. Uno de los grandes beneficios de las obras literarias es que hay pasajes escritos en la juventud -o bien, en una fase de la madurez en que la juventud se recuerda con cierto calor o añoranza. Y, quiéralo o no el autor, esos pasajes superan cualquier desilusión o contradicción posterior. Tal es el caso de "Poesía e historia", uno de los mejores testimonios de Octavio Paz, y del cual estas palabras nos servirán ahora de conclusión:

En México los que teníamos veinticinco años en 1940 oponíamos mentalmente las figuras de nuestros poetas a las de los tiranos: Darío, Machado y Juan Ramón nos consolaban de los Franco, los Somoza y los Trujillo. Pero la poesía no era, para nosotros, ni un refugio ni una fuga: era una conciencia y una fidelidad. Aquello que la historia había separado, ella lo unía... la poesía era la continuidad $^{21}$.

Peter G. Earle University of Pennsylvania

\section{BIBLIOGRAFÍA}

Brown, Norman O. 1959. Life against Death. Random House, New York.

CAMPBelL, JEREMY 1982. Grammatical Man: Information, Entropy, Language and Life. Simon and Schuster, New York.

Fuentes, Carlos 1970. Casa con dos puertas. J. Mortiz, México.

García Márquez, Gabriel 1967. Cien años de soledad. Sudamericana, Buenos Aires.

Garfias, Francisco 1991. "Desvalorización de ideologías", Excelsior, 7 de julio.

Groia, Dana 1991. "Can Poetry Matter?”, The Athlantic Monthly, núm. 5, 94-106.

Ortega y Gasset, José 1963. "Epistolario entre Ortega y Curtius", ROcc, núm. 6, 329-341.

Paz, Octavio 1967. Piedra de sol. Tezontle, México.

-, 1959. El laberinto de la soledad. F.C.E., México.

21 PAZ 1983, p. 48. 
Paz Octavio 1967. El arco y la lira, F.C.E., México.

- 1974. Los hijos del limo. Seix Barral, Barcelona.

-, 1976. Vuelta. Seix Barral, Barcelona.

- 1978. Pasado en claro. F.C.E., México.

_ , 1979a. "Alrededores de la literatura hispanoamericana", en In/mediaciones. Seix Barral, Barcelona, pp. 25-37.

— , 1979b. "Introito a guisa de carpocapsa saltitans", en A. Jiménez (ed.), Nueva picardía mexicana. Editores Mexicanos Unidos, México, pp. 9-11, $39-40,157-159,260-265$.

_ 1983. Sombras de obras. Seix Barral, Barcelona.

- 1987. Árbol adentro. Seix Barral, Barcelona.

—, 1988. Primeras letras (1931-1943). Ed. Enrico Mario Santí. Vuelta México.

—, 1991. "La búsqueda del presente", Vuelta, núm. 170, 10-14.

Posse, Abel 1989. Daimón. Plaza y Janés, Barcelona. 